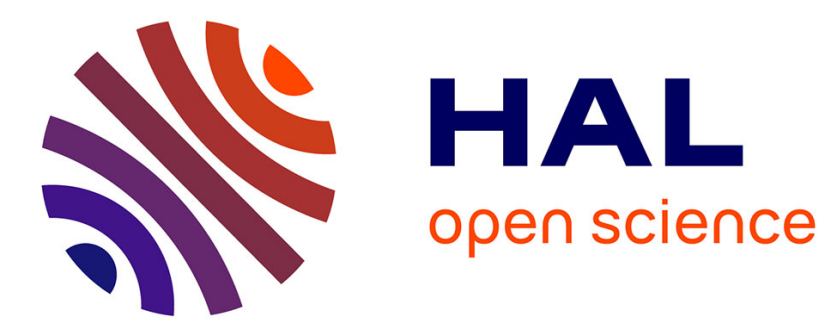

\title{
Performance Improvements of a Regional Aircraft by Riblets and Natural Laminar Flow
}

Pietro Catalano, Donato de Rosa, Benedetto Mele, Renato Tognaccini, Frédéric Moens

\section{> To cite this version:}

Pietro Catalano, Donato de Rosa, Benedetto Mele, Renato Tognaccini, Frédéric Moens. Performance Improvements of a Regional Aircraft by Riblets and Natural Laminar Flow. Journal of Aircraft, 2019, 57 (1), pp.29-40. 10.2514/1.C035445 . hal-02472781

\section{HAL Id: hal-02472781 \\ https://hal.science/hal-02472781}

Submitted on 10 Feb 2020

HAL is a multi-disciplinary open access archive for the deposit and dissemination of scientific research documents, whether they are published or not. The documents may come from teaching and research institutions in France or abroad, or from public or private research centers.
L'archive ouverte pluridisciplinaire HAL, est destinée au dépôt et à la diffusion de documents scientifiques de niveau recherche, publiés ou non, émanant des établissements d'enseignement et de recherche français ou étrangers, des laboratoires publics ou privés. 


\title{
Performance Improvements of a Regional Aircraft by Riblets and Natural Laminar Flow
}

\author{
P. Catalano* and D. de Rosa \\ CIRA, Italian Aerospace Research Center, 81043 Capua (CE), Italy \\ B. Mele \pm and R. Tognaccini $\underline{\S}$ \\ “Federico II" University, 80125 Napoli, Italy \\ and \\ F. MoensI \\ ONERA-The French Aerospace Lab, 92190 Meudon, France
}

\begin{abstract}
https://doi.org/10.2514/1.C035445
The application of riblets on a typical regional turboprop configuration is discussed in this paper. The effect of the riblets is modeled as a singular roughness problem by a proper boundary condition at the wall. The model, already proposed in a previous paper, is briefly described. The drag prediction capabilities are verified by showing some airfoil flow applications. Then a typical wing-body of a regional aircraft is considered. The configuration has been designed to have extended natural laminar flow in cruise conditions. Riblets are applied at flow specifications representative of cruise in combination with the natural laminar flow technology and in climb/descent conditions. A comparison of the two technologies in terms of drag reduction is presented. Their combined application can result in a cruise drag reduction of more than $20 \%$. The resulting fuel savings during a typical operational day are evaluated.
\end{abstract}

\section{Introduction}

$\mathbf{T}$ ODAY there is renewed interest in drag reduction mechanisms. Indeed, current concern over environmental pollution is forcing manufacturers to reduce pollutant emissions not only in the industrial field but also in the transport sector. Several methods for reducing viscous drag have been studied during the last three decades. These are used to delay laminar-boundary-layer transition or to modify the turbulence structures of the boundary layer. Some methods are active controls, and others are passive as they do not require any energy use. Focusing on passive devices, the natural laminar flow (NLF) technology aims at extending the laminar region as much as possible. Instead the riblets, consisting of streamwise grooved surfaces, are able to reduce friction drag in the turbulent part of the flow.

Naturalistic studies suggested that shark skin covered by streamwise microscopic ridges is able to reduce friction in turbulent flows. The first fundamental studies on riblets were performed at NASA in 1970s and 1980s [1]. The drag reduction mechanism is linked to the shape of the riblets, and, in particular, effective results have been achieved by $V$-shaped geometries [2] with riblets having sharp triangular ridges. The experiments by Bechert et al. [3,4] and the studies by Luchini et al. [5] in 1990s have clarified the drag reduction mechanism. This can be reduced to a shift of the velocity profile in the turbulent region of a boundary layer.

The effect is essentially local (i.e. depends on the local Reynolds number), and the optimum riblets height is $h^{+} \approx 15$, where the superscript "+" means that the height is made nondimensional by

\footnotetext{
*Research Engineer, Fluid Mechanics Unit; p.catalano@ cira.it.

${ }^{\dagger}$ Research Engineer, Fluid Mechanics Unit; d.derosa@ cira.it.

¥Associate Researcher, Dipartimento di Ingegneria Aerospaziale; benmele@ unina.it

${ }^{\S}$ Associate Professor, Dipartimento di Ingegneria Aerospaziale; rtogna@ unina.it. Senior Member AIAA.

"Research Engineer, Aerodynamics, Aeroelasticity, Aeroacoustics Department; frederic.moens@onera.fr. Member AIAA.
}

viscous wall quantities. First experiments on airfoils did not show any significant effect of a variable pressure distribution on riblet performance [2]. Successively a number of experiments [6-8] proposed that most of drag reduction resulted from the airfoil upper surface, suggesting increased effectiveness of riblets in adverse pressure gradients. Experimental analyses on airfoils of wind turbine $[9,10]$ proposed similar conclusions. Other experiments investigating flow over flat plate under an adverse pressure gradient confirmed this stilldebated behavior [11-13]. Boomsma and Sotiropoulos [13] in particular investigated, by large-eddy simulation (LES), the effect on riblet performance of mild adverse pressure gradient in flat plate flow. The authors found an additional drag reduction (1-1.5\%) in agreement with the experimental results of Debisschop and Nieuwstadt [12]. Koeplin et al. [14] proposed a model for turbomachinery applications to take into account the misalignment of riblets with the freestream velocity and presented a pressure correction based on a local Clauser parameter. Mele and Tognaccini [15], adopting the slip length concept, provided a contribution to understand why riblet performance can improve in case of airfoil flow. In particular, they found a reduction of the boundary-layer displacement thickness due to riblets, more evident in presence of pressure gradient, which implies a reduction of form drag.

There is a lack of literature on riblets in presence of pressure gradient and more generally for the application of this device to complex configurations at high Reynolds numbers. These flows can still be studied only by methods based on the Reynolds-averaged Navier-Stokes (RANS) equations that, at least for mainly attached flows, provide accuracy comparable to LES $[\underline{16}, 17]$ for the mean quantities. However, the RANS methods cannot resolve the scales of riblets (microns in aeronautical applications), and the effect of the riblets needs to be modeled. Mele and Tognaccini [18] have introduced the idea to model the effect of the riblets by a proper boundary condition at the wall such as usually done for the effect of roughness. The proposed boundary condition has been implemented in two unsteady RANS (URANS) flow solvers, the Italian Aerospace Research Center (CIRA) in-house-developed UZEN code [19,20] and FLOWer, a code developed at German Aerospace Center (DLR) and used by University of Napoli. A relevant number of two-dimensional (2D) and three-dimensional (3D) test cases have been carried out in order to validate and evaluate the model [21-24].

In aeronautics, riblets have been studied in several flight tests with interesting results in terms of fuel consumption. Nevertheless, they have never been adopted in commercial applications. This is mainly 
due to manufacturing and maintenance issues that seem to be possible to address by advanced technologies $[25,26]$. Very promising are, for instance, contactless manufacturing technologies [27]. USAF recently launched a research program with the aim to retrofit with riblets its transport fleet [28]. This paper deals with the effect of the riblets on the performances of a real aircraft when combined with the NLF technology [29]. Numerical simulations have been performed at different flow conditions representative of the characteristics points of a typical mission of a regional aircraft. The main goal is to evaluate the gain achievable by the riblets over an entire mission of the aircraft.

The paper is structured as follows. The modeling of the effect of the riblets is discussed in Sec. II, and the results are presented in Secs. III-V. First, some relevant $2 \overline{\mathrm{D}}$ test cases are analyzed, and then the application of riblets to the regional aircraft is discussed. The riblets are discussed in conjunction with the NLF technology. Finally, the weight that a new-generation turboprop aircraft could save is also estimated. The conclusions are drawn in Sec. VI.

\section{Modeling the Effect of Riblets}

It has been shown that riblets induce a displacement of the turbulence eddies with respect to the mean flow, leading to a reduction of the momentum transfer to the wall with a consequent drag reduction $[\underline{4}, \underline{5}, 30]$. This mechanism is confined very near to the surface and induces a drag increase if riblets are large enough to interact directly with the turbulence structures. In practice, the effect of riblets is the shift of the origin of the velocity profile, that is, a shift of the constant of the well-known logarithmic law of wall:

$$
U^{+}=\frac{1}{\kappa_{a}} \log \left(y^{+}\right)+B-\Delta U^{+}
$$

where the superscript " + " specifies nondimensional quantities obtained by using wall variables, $\kappa_{a}$ is the Kármán constant, and $B$ measures the influence of the wall on the velocity profile. For an incompressible flow without pressure gradient, the $\Delta U^{+}$(and hence the value of $B$ ) can be related to the difference in the friction coefficients. In fact, at the edge of the boundary layer

$\Delta U_{E}^{+}=\left(U_{E}^{+}\right)_{R}-\left(U_{E}^{+}\right)_{S}=\left(\frac{1}{\kappa_{a}} \log \left(\delta^{+}\right)\right)_{R}-\left(\frac{1}{\kappa_{a}} \log \left(\delta^{+}\right)\right)_{S}+\Delta U^{+}$

where the subscripts $S$ and $R$ refer to the smooth and to the configuration equipped with riblets. By assuming that $\delta^{+}$is the same and considering that for the incompressible flow over a flat plate $U_{E} \approx$ $U_{\infty}$ since

$$
1-\left(\frac{U_{E}}{U_{\infty}}\right)^{2}=\frac{2 \gamma}{\gamma-1} \frac{P_{E}-P_{\infty}}{\rho U_{\infty}^{2}}
$$

the velocity shift is obtained as

$$
\Delta U^{+}=\left(\sqrt{\frac{2}{C_{f}}}\right)_{R}-\left(\sqrt{\frac{2}{C_{f}}}\right)_{S}
$$

Equation (1) is the same formula describing the effects of wall roughness on turbulent flows. The difference is that, in the case of roughness, $\Delta U^{+}$is usually positive, returning an increase of drag, whereas riblets provide negative values of $\Delta U^{+}$with a reduction of the skin friction. Tani [31] re-analyzed the classical experimental data of Nikuradse [32] on turbulent flows over rough walls. He focused his attention on the transitional roughness regime that is characterized by a roughness height not large enough for a fully rough behavior (usually the transitional roughness is defined for nondimensional roughness height $k_{s}^{+}<50$ ). He realized that sand roughness induces a reduction of skin friction if $k_{s}^{+}$, which is often defined as roughness Reynolds number, is lower than about 6 . Above this critical value, the sand roughness induces an increase of drag. Tani already noted that this behavior is surprisingly similar to riblet effects that, however, induce a much greater drag reduction. On the other hand, he emphasized that, unlike riblets, sand roughness is insensitive to flow direction. The well-known wall boundary condition of Wilcox for the $k-\omega$ turbulence models family [33] is widely adopted for simulating rough walls. Wilcox derived his boundary condition from Saffman [34], who first observed that, approaching the surface, the differential equations of the $\kappa-\omega$ turbulence models possess a kind of solution that returns a finite value for $\omega$ at the surface. This value can be, in principle, any value that correctly reproduces the logarithmic law of smooth, rough, or grooved wall. Saffman proposed the following boundary condition for $\omega$ at the wall:

$$
\omega=\frac{\rho u_{\tau}^{2}}{\mu} \cdot S_{R}\left(k_{s}^{+}\right)=\frac{\tau_{w}}{\mu} \cdot S_{R}\left(k_{s}^{+}\right)
$$

where $\rho$ is the density, $u_{\tau}=\sqrt{\tau_{w} / \rho}$ is the friction velocity ( $\tau_{w}$ is the wall shear stress), and $\mu$ is the dynamic viscosity. Using Eq. (5) and from the analysis of the experimental results of Nikuradse, Wilcox derived his condition for $S_{R}$ on rough walls:

$$
S_{R}=\left\{\begin{array}{cc}
\left(50 / k_{s}^{+}\right)^{2} & k_{s}^{+}<25, \\
100 / k_{s}^{+} & k_{s}^{+} \geqslant 25
\end{array}\right.
$$

Thus $\omega$ at the wall depends on $\Delta U^{+}$or equivalently on $S_{R}=S_{R}\left(\Delta U^{+}\right)$and depends on the nature of the wall. In the case of transitional roughness, $S_{R}\left(\Delta U^{+}\right)$has been obtained verifying, by numerical experiments, the correct value of $S_{R}$, providing the $\Delta U^{+}$measured by Tani. A simple bell-shaped function has been used to fit the new obtained values for $S_{R}$ :

$$
S_{R}=\frac{C_{1}}{\left(k_{s}^{+}-C_{2}\right)^{2 n}+C_{3}}
$$

where $C_{1}=1.666 \cdot 10^{3} ; \quad C_{2}=3.25 ; \quad C_{3}=0.1 ; \quad$ and $n=1$. Equation (7) recovers for $k_{s}^{+}=0$ and $k_{s}^{+}=6.5$ the $S_{R}$ value for smooth wall. The same Eq. (7) with different coefficients and written as a function of $l_{g}^{+}=\sqrt{A_{g}^{+}}$, where $A_{g}^{+}$is the riblet nondimensional cross-sectional area, can be used to simulate the effects of an arbitrary riblet family. In fact, following García-Mayoral and Jiménez [35], $l_{g}^{+}$gives a better characterization of riblet performance than the nondimensional riblet spacing $s^{+}$and height $h^{+}$(Fig. 1). They found that the adoption of $l_{g}^{+}$collapses riblet experimental data into a compact group of similar curves. Thus, in the case of riblets, Eq. (7) can be rewritten as:

$$
S_{R}=\frac{C_{1}}{\left(l_{g}^{+}-C_{2}\right)^{2 n}+C_{3}}
$$

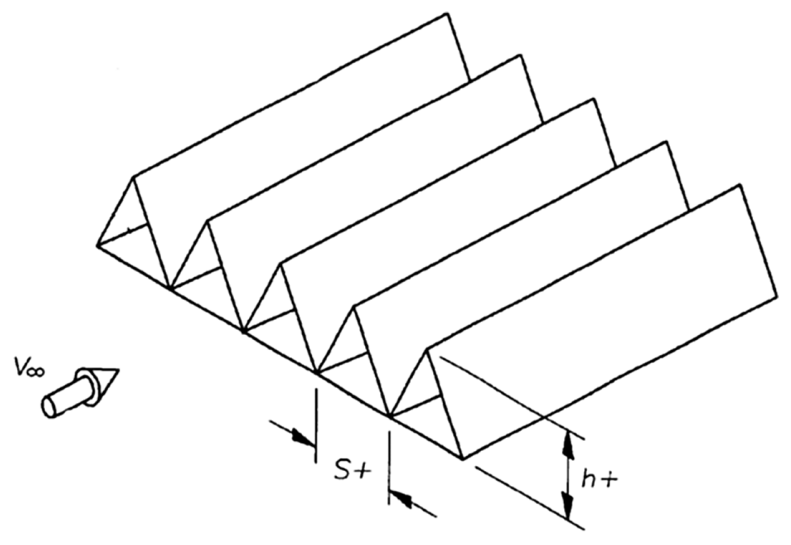

Fig. 1 "V-shaped" riblets. 
The coefficients have been obtained by numerical experiments matching the experimental data reported in [35]: $C_{1}=2.5 \cdot 10^{8}$; $C_{2}=10.5 ; C_{3}=1 . \cdot 10^{-3} ; n=3$. The geometry and size of the riblet enter Eq. (8) through $l_{g}^{+}$. In particular the value of $l_{g}^{+}=C_{2}=10.5$, corresponding to the maximum value of the function $S_{R}$, defines the "optimal" size of the riblet. In the case of the riblet family reported by Walsh [2], manufactured by $3 \mathrm{M}$ company, with a symmetric V-grooved section (Fig. 1), the relation between $l_{g}^{+}, s^{+}$, and $h^{+}$is $s^{+}=h^{+}=\sqrt{2} l_{g}^{+}$.

\section{Two-Dimensional Test Cases}

The model described in the previous section has been first implemented in FLOWer, a code developed at DLR and used by University of Napoli. FLOWer code solves the compressible 3D steady and unsteady RANS equations on block-structured meshes around complex aerodynamic configurations. In both $2 \mathrm{D}$ and $3 \mathrm{D}$ simulations the spatial discretization adopted was a central finite volume formulation with explicit blended second- and fourth-order artificial dissipation. Time integration is carried out by an explicit hybrid multistage Runge-Kutta scheme. The $\kappa-\omega$ SST turbulence model, modified for considering riblets, was adopted. Then the model has been implemented in the CIRA in-house-developed UZEN code [19,20], a flow solver with a numerics and a data structure similar to FLO $\overline{\mathrm{Wer}}$. A basic validation has been performed for a flat plate, and for 2D flows in previous papers $[18,21,22,24,29]$, obtaining results consistent with theoretical considerations and in good agreement with the available experimental data. Accurate numerical computing and experimental measuring of small differences in drag coefficient is a critical issue, and then further 2D test cases are here presented and compared with available experiments. In particular, results for an airfoil in subsonic and transonic conditions and for the incompressible flow around a wind turbine section are considered.

\section{A. CAST7 Airfoil}

The test case is very interesting because it shows the possible variation of riblet performance from subsonic to transonic flow. In what follows the results obtained by UZEN code are shown as further validation of the model for riblet simulations described in Sec. II. Experimental data [36] are available at Reynolds number $3 \times 10^{6}$, $\alpha=0^{\circ}$, and Mach numbers $0.65,0.70$, and 0.76 . The configuration has been considered with the transition imposed at $5 \%$ of the chord on both the upper and lower surfaces, and the $\kappa-\omega$ SST turbulence model has been applied. The riblets are installed from the $15 \%$ of the chord.

A C-topology grid with $576 \times 192$ cells has been employed. The convergence of the drag coefficient at the highest Mach number is reported in Fig. 2a. The variation of the $C_{D}$ stays well within the drag count for either the smooth airfoil or the configurations with riblets installed. The $y^{+}$obtained on the upper surface of the airfoil is shown in Fig. 2b. The viscous coordinate is slightly greater than one only in the leading edge zone. It is worth noting that the effect of applying riblets with $h=0.023 \mathrm{~mm}$ is to decrease $y^{+}$(i.e., decrease the friction), whereas riblets with $h=0.051 \mathrm{~mm}$ provide a slight increase in $y^{+}$(i.e., an increase in friction).

The drag coefficient obtained for the smooth configuration and with riblets of $h=0.023 \mathrm{~mm}$ and $h=0.051 \mathrm{~mm}$ is plotted as a function of the Mach number in Fig. 3a. The results achieved are in a reasonable agreement with the experimental data. The behavior with the Mach number is well predicted, but the $C_{D}$ is overpredicted for the smooth configuration and underpredicted for the riblets-on configurations with respect to the experiments. In particular, the drag coefficient decreases at all the Mach numbers for the riblets with $h=0.023 \mathrm{~mm}$ in both experimental and numerical data. Instead the riblets with $h=0.051 \mathrm{~mm}$ present an increase of $C_{D}$ in the experiments, whereas the numerical simulations provide a slight decrease of drag at Mach 0.65 and 0.70 and a slight decrease at Mach 0.76 .

The $C_{D}$ measured with riblets of $h=0.051 \mathrm{~mm}$ is compared with the numerical results achieved with an increasing height of the riblets in Fig. 3b. The matching with the experimental values is obtained applying riblets with $h=0.056 \mathrm{~mm}$ at Mach $0.65, h=0.059 \mathrm{~mm}$ at Mach 0.70 , and $h=0.064 \mathrm{~mm}$ at Mach 0.76 . It turns out that the model and the numerics employed in the simulations require riblets somehow higher to achieve the same variation of drag as in the experiments. As an example, the friction coefficient for the smooth configuration and for the configuration with riblets of $0.023 \mathrm{~mm}$ height is presented in the left plot of Fig. 4 . The decrease of the friction coefficient is evident and there is also a slight effect on location and strength of the shock. The physical height of a symmetric $\mathrm{V}$-shaped riblet can be related through to the viscous height $h^{+}$using the following relation:

$$
h^{+}=\frac{h u_{\tau} \rho}{\mu}=\frac{h}{L_{\mathrm{REF}}} R e_{\infty} \sqrt{\frac{C_{F}}{2}} \sqrt{\frac{\rho}{\rho_{\infty}}} \frac{\mu_{\infty}}{\mu}
$$

Equation ( $\underline{\text { g) }}$ is useful to evaluate the physical height of V-shaped riblets corresponding to the "optimal" $h^{+}$. This is shown in the right

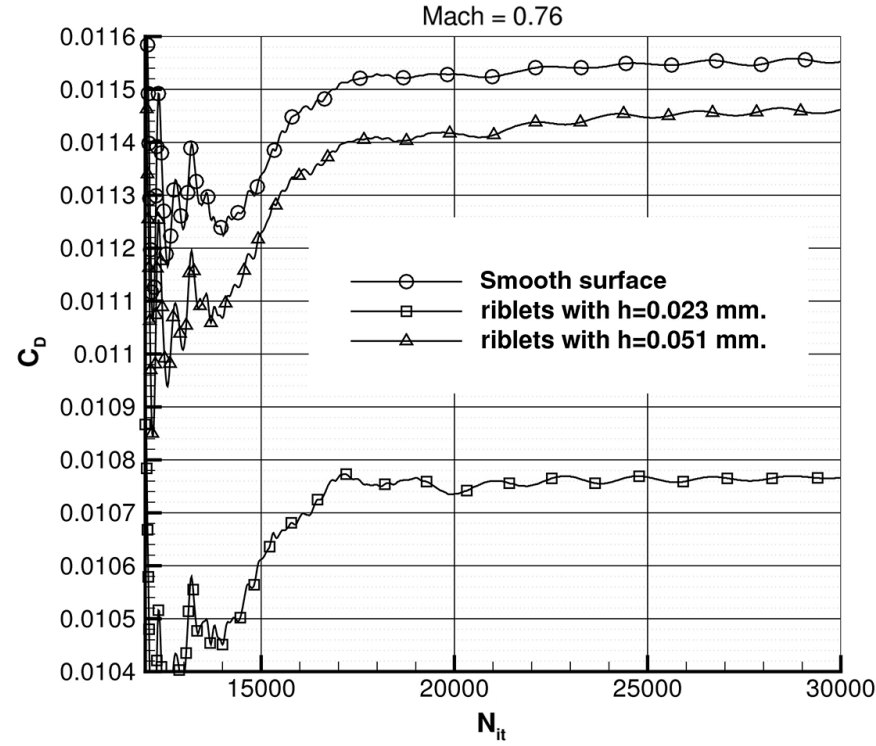

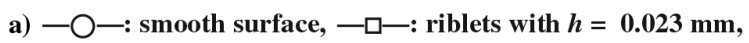
$-\Delta$-: riblets with $h=0.051 \mathrm{~mm}$

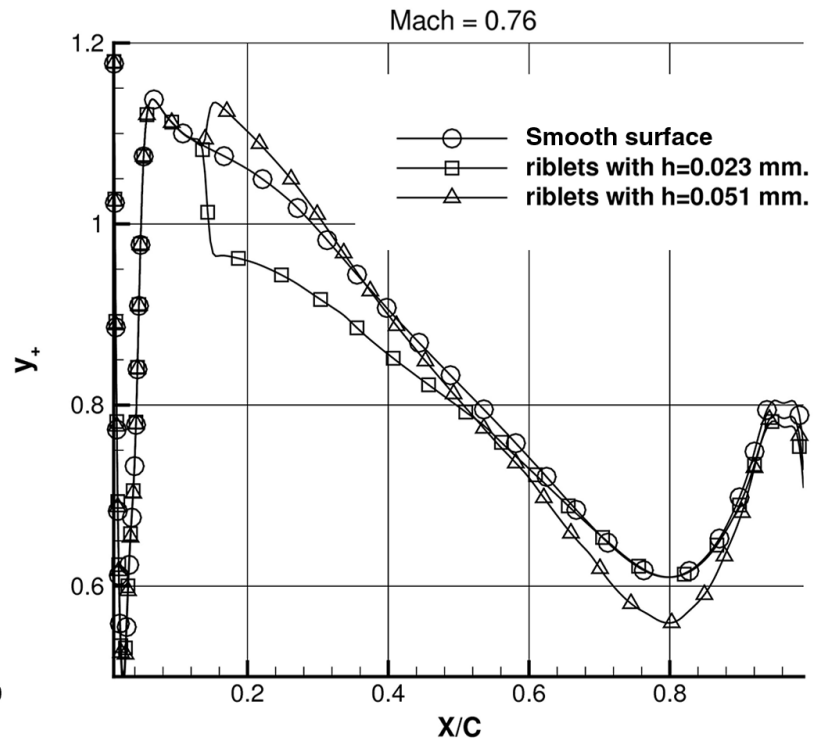

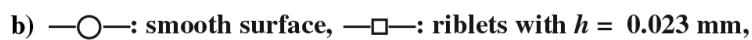
$-\Delta-$ : riblets with $h=0.051 \mathrm{~mm}$

Fig. 2 CAST-7 airfoil at Mach $=0.76, R e=3 \times 10^{6}$, and $\alpha=0$ : assessment of the grid. 


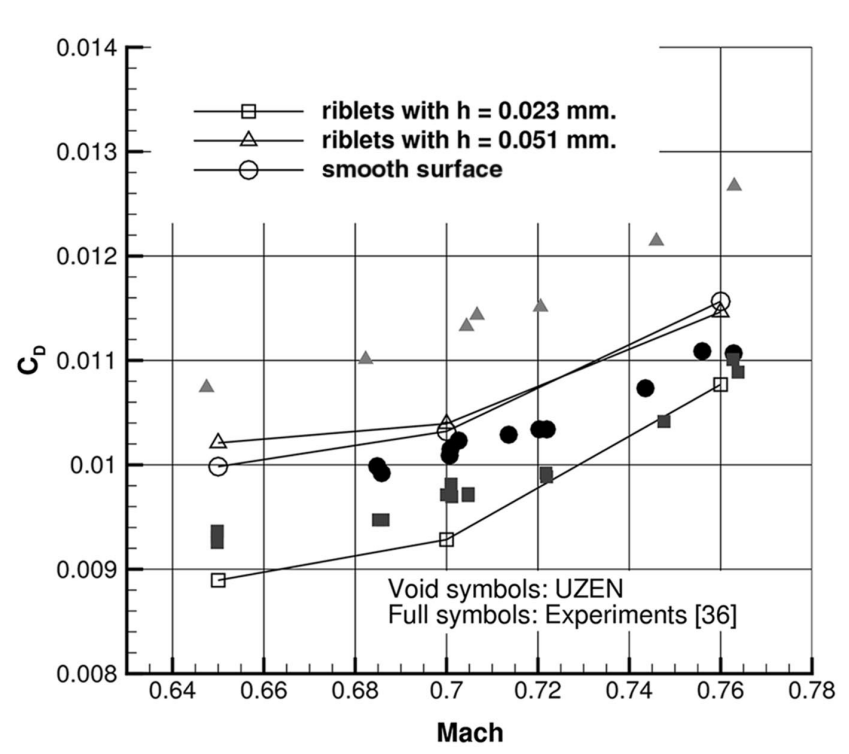

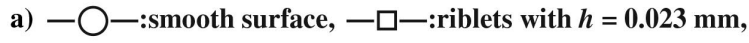
$-\Delta$ 一:riblets with $h=0.051 \mathrm{~mm}$

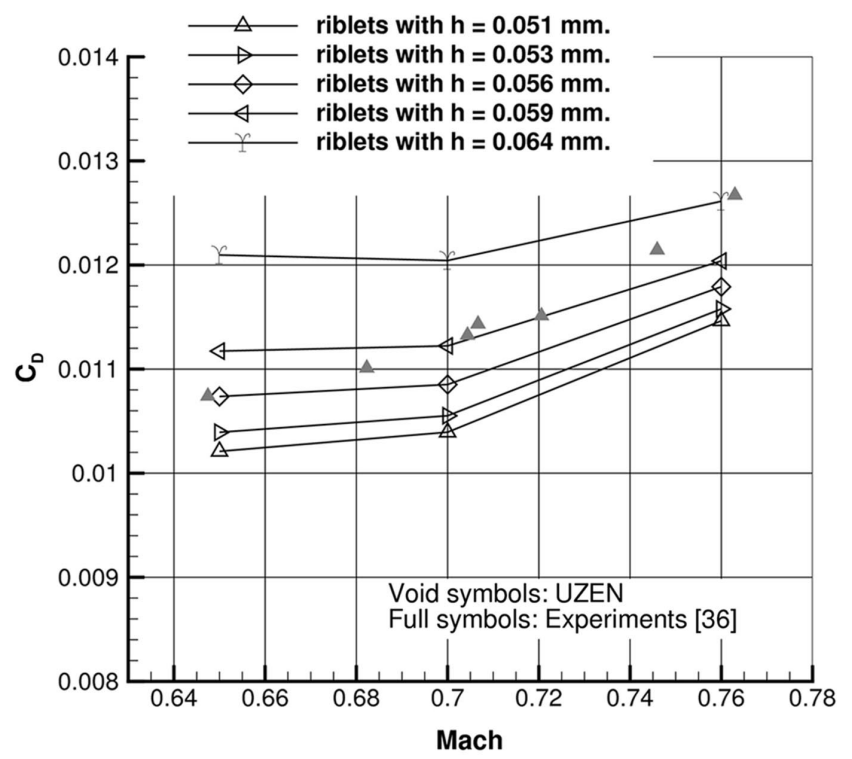

b) $-\Delta$ 一:riblets with $h=0.051 \mathrm{~mm}, \longrightarrow$-:riblets with $h=0.053 \mathrm{~mm}$,

——:riblets with $h=0.056 \mathrm{~mm}, 乙 \triangleleft$-riblets with $h=0.059 \mathrm{~mm}$,

——: :riblets with $h=0.064 \mathrm{~mm}$

Fig. 3 CAST-7 airfoil at $R e=3 \times 10^{6}$, and $\alpha=0$ : drag coefficient. Full symbols: experiments [36]; void symbols: numerical.

plot of Fig. 4 at the three Mach numbers taken into consideration. The height increases in a nonlinear way with the Mach number. It also increases along the chord on both the upper and lower surfaces of the airfoil and presents a spike, almost doubling, close to the shock wave.

\section{B. DU 96-W-180 Airfoil}

The incompressible flow around DU 96-W-180 airfoil is another interesting test case for a further validation of riblets model due to the availability of two different experiments performed at various Reynolds numbers and angles of attack. Also the presence of a laminar separation bubble is useful to test the behavior of the model in offdesign conditions. The results provided in this section were obtained by FLOWer code modified for riblet simulations.

Chamorro et al. [9] tested various riblet sizes and shapes provided by $3 \mathrm{M}$ company on a DU 96-W-180 airfoil. The experiments were performed in low-speed conditions at a Reynolds number $2.2 \times 10^{6}$ referred to $1 \mathrm{~m}$ airfoil chord and varying the lift coefficients from 0.25 to 1.14 . The same airfoil was studied in the experiments of Sareen et al. [10]. They also tested various riblet sizes provided by $3 \mathrm{M}$ company at three different Reynolds numbers, $1.0 \times 10^{6}, 1.5 \times 10^{6}$, and $1.85 \times 10^{6}$, referred to $0.457 \mathrm{~m}$ airfoil chord.

The effect of full or partial riblet coverage on the airfoil has also been investigated in both experiments. The authors of the experiments calculated, by Xfoil simulations, the transition to turbulence over the clean airfoil in its operational range, and then, in the case of partial riblet coverage, the riblet film was applied starting from $40 \%$ of the airfoil chord on the upper surface and $70 \%$ on the lower surface. Sareen et al. [10] also determined the experimental separation and reattachment points and reported an oil flow visualization of the detected laminar separation bubble at $\alpha=6^{\circ}$ and Reynolds number $1.5 \times 10^{6}$. The present numerical simulations have been performed at the same flow conditions as the experiments with partial riblet

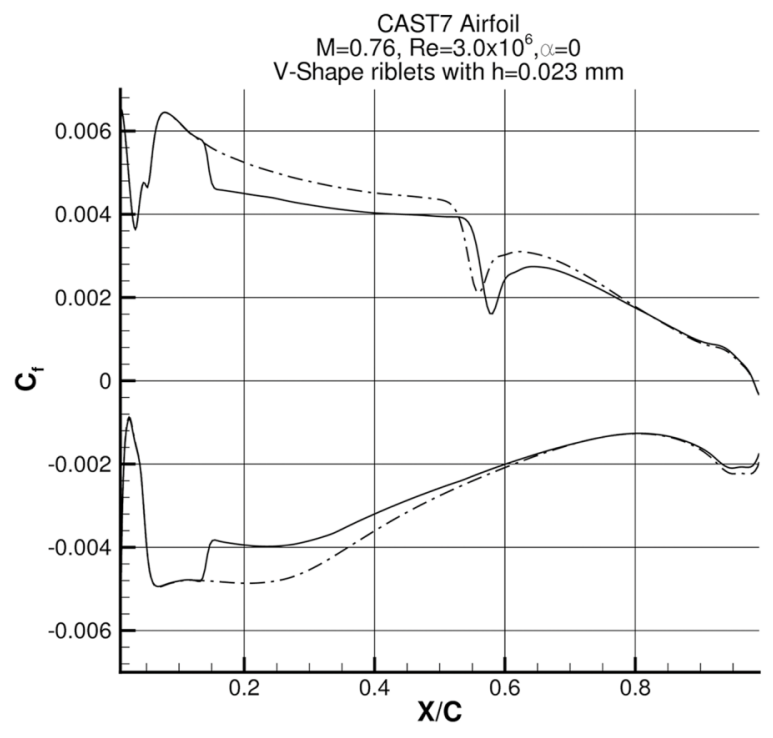

a) $C_{f}$.---: riblets $\mathrm{OFF}$; —

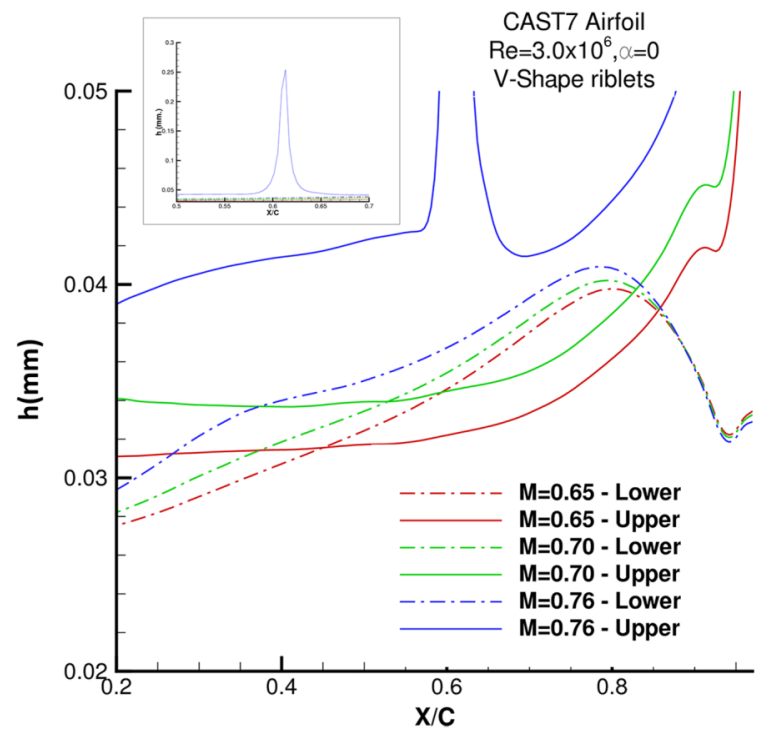

b) Physical height corresponding to "optimal" $h^{+}$

Fig. 4 CAST-7 airfoil at $R e=3 \times 10^{6}$, and $\alpha=0$ : skin friction coefficient and height of the riblets. 


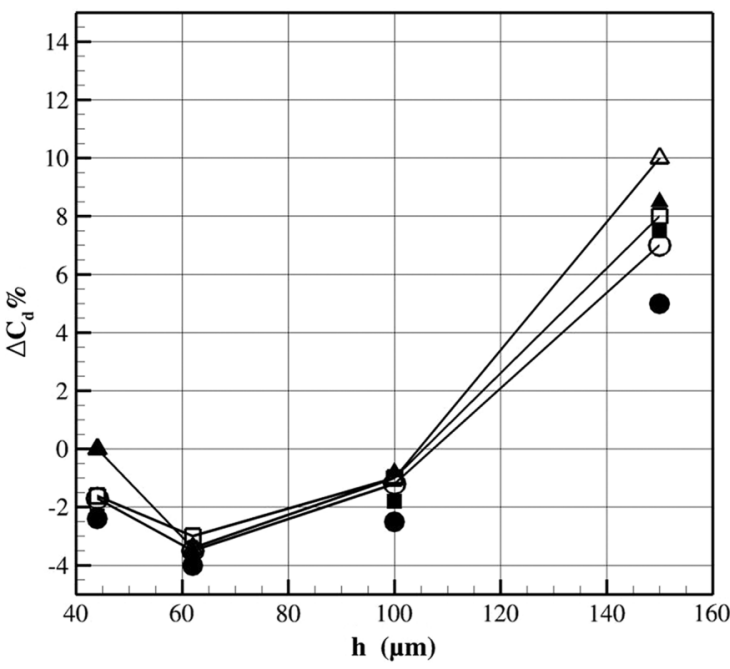

a) $R e_{\infty}=1.5 \times 10^{6} . \square: C_{l}=0.75, \circ: C_{l}=0.875, \triangle: C_{l}=1$

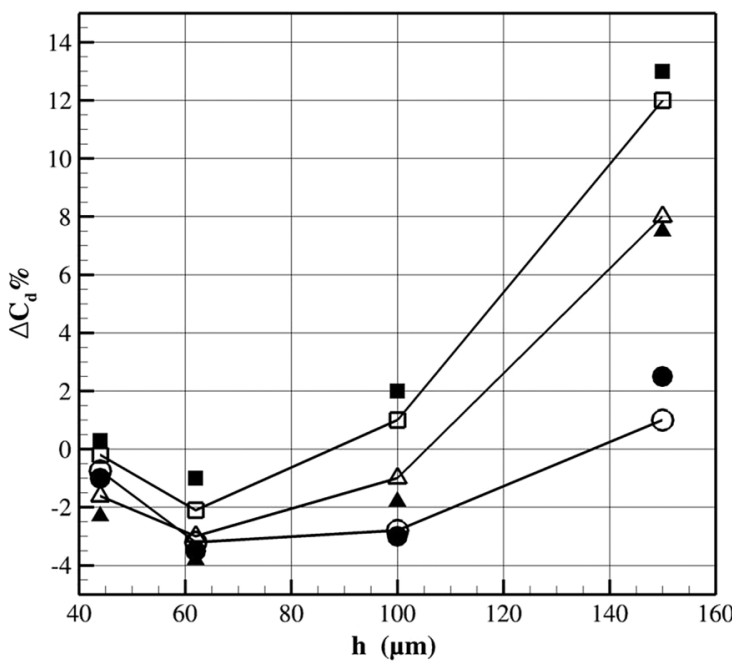

b) $C_{l}=0: 75 . \circ: R e_{\infty}=1.5 \times 10^{6}, \triangle: R e_{\infty}=1.85 \times 10^{6}$, $\square: R e_{\infty}=1 \times 106$

Fig. 5 DU 96-W-180 airfoil. Computed and experimental drag reduction vs riblet height. Void symbols: numerical; full symbols: experimental.

coverage. All calculations have been carried out at $M_{\infty}=0.1$ and specifying the transition on the upper and lower surface at the same position reported in the experiments. In the laminar zone the production terms of the turbulence equations are set to zero; such transition treatment guarantees optimal flow prediction in case of laminar separation bubbles [19]. The computed drag reduction versus riblet height at $R e_{\infty}=1.5 \times 10^{6}$ is compared with the measurements of Sareen et al. [10] in Fig. 5. A satisfactory agreement is shown. The achieved maximum drag reduction is $3-4 \%$ and is strictly linked to the extension of the turbulent region that depends on lift coefficient. The effect of $C_{l}$ on the computed drag reduction is summarized in Fig. 5a. The effect of Reynolds number is shown in Fig. 5b, where the computed and measured drag reduction versus riblet height at $C_{l}=$ 0.75 is shown for three different Reynolds numbers. In Fig. $\underline{6}$ the computed drag reduction versus $C_{l}$ is compared with the experiments of Chamorro et al. [9] performed at $R e_{\infty}=2.2 \times 10^{6}(1 \mathrm{~m}$ reference chord) with $80 \mu \mathrm{m}$ symmetric V-grooved riblets. Also in this case a satisfactory agreement between computation and experimental data is achieved. The computed skin friction coefficients with and without riblets at $R e_{\infty}=1.5 \times 10^{6}$ and $C_{l}=0.75,0.875$, and 1.0 are shown in Fig. 7. Detected laminar separation bubbles are clearly visible, and the separation and reattachment points are in good agreement with experimental data. It is worth noting that the whole effect of riblets on

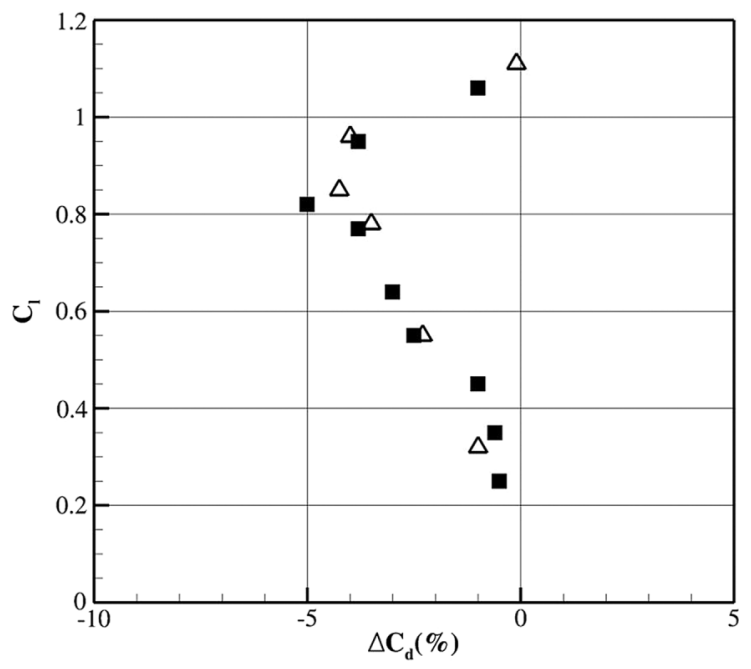

Fig. 6 DU 96-W-180 airfoil with symmetric V-grooved riblets of $h=s=80 \mu \mathrm{m}, R e_{\infty}=2.2 \times 10^{6}$. Computed and experimental drag reduction vs lift coefficient. $\_\Delta$ —: computed; $\square$ : experiments [9]. skin friction coefficients is in the attached flow zone. The skin friction seems to be not influenced inside the laminar separation bubble.

\section{Riblets and NLF Performance on a Regional Aircraft Configuration}

A wing-body configuration of a typical regional aircraft (Fig. 8) has been taken into consideration [29]. The wing has been designed following the process used for a transonic application [37]. The airfoil sections are designed to have an extended NLF in cruise conditions and have been obtained from a multipoint numerical optimization process [38]. Then, the wing twist has been optimized in order to take into account low-speed performance requirements. A structured multiblock grid made of 128 blocks for a total number of $23 \times 10^{6}$ points have been generated and used to perform RANS simulations. The outboard wing is discretized spanwise by 97 sections, 41 sections being used for the inboard wing. Around the different solid walls, an external layer of 72 nodes has been considered to catch the boundary layer developed.

As a mean value, the number of nodes in the boundary layer is around 48. One airfoil section is made of 88 points on each surface (upper and lower surface), with special refinements at nose and trailing edge.

In Fig. 9 the $y^{+}$distribution on the wing-body shows that it satisfies the requirements for an accurate computation inside the boundary layer.

Cruise and climb/descent conditions have been investigated in order to cover the mission typical of a regional aircraft. The main aim is to evaluate the gain in terms of aerodynamic drag that could be achieved by applying the riblets to such a configuration.

Different cases have been considered in order to assess the effect of the riblets in combination with an NLF. Riblets are first applied with the assumption of "fully turbulent" flow and then in the case of laminar flow for a large part of the wing according to the NLF technology. In the case of fully turbulent assumption, the riblets have been installed only on wing, only on body, and on the entire configuration in order to determine the zones of the configuration where the riblets are more effective. Resuming, the following conditions have been taken into account:

1) Cruise condition:

a) Fully turbulent flow:

i) No riblets

ii) Riblets on both wing and fuselage

iii) Riblets only on wing

iv) Riblets only on fuselage

b) Laminar flow:

i) No riblets 


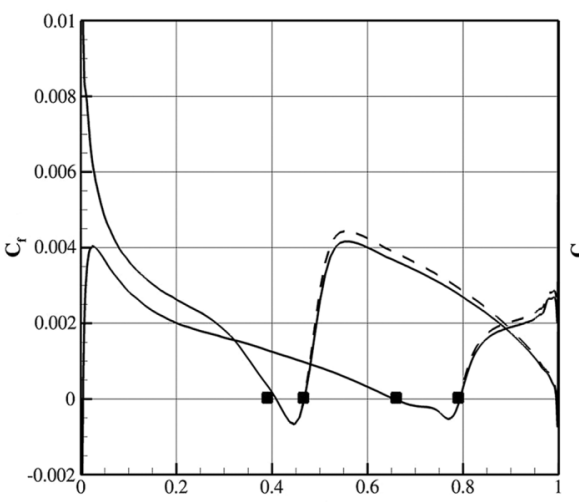

a) $C_{l}=0.75$

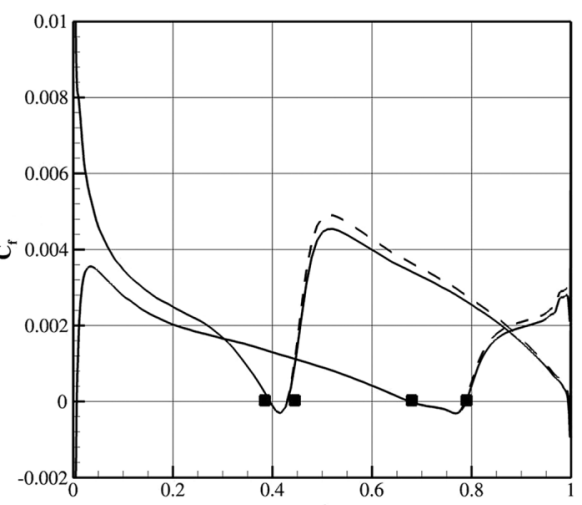

b) $C_{l}=0.875$

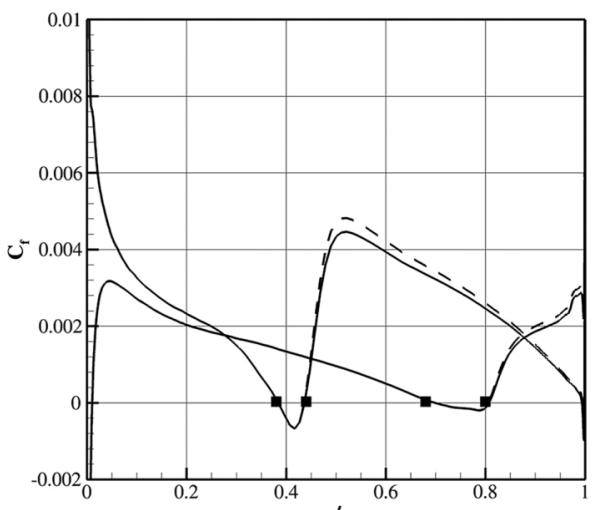

c) $C_{l}=1.0$

$\mathbf{x} / \mathbf{c}$

Fig. 7 DU 96-W-180 airfoil, $R e_{\infty}=1.5 \times 10^{6}$. Computed skin friction coefficients. --: computed with riblets $h=62 \mu \mathrm{m}$; - - computed without riblets; $\square$ : experimental separation and reattachment points without riblets.

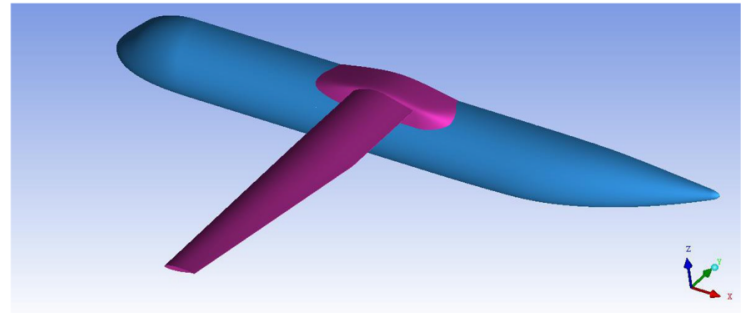

a) Geometry

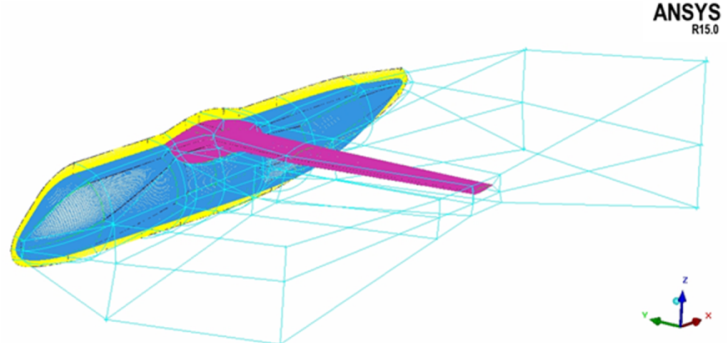

b) Computational grid

Fig. 8 Regional aircraft configuration.

ii) Riblets on both turbulent part of the wing and fuselage

2) Climb/descent conditions:

a) Fully turbulent flow:

i) Riblets on both wing and fuselage

ii) Riblets only on wing

iii) Riblets only on fuselage

Finally, the estimate gain in terms of saving of weight for an operative day is calculated adopting the Breguet formula.

\section{A. Cruise Conditions with Fully Turbulent Assumption}

A flow condition corresponding to Mach number 0.50 and Reynolds number (based on the chord of the wing) of $3.0 \times 10^{7}$ has been considered.

A grid convergence analysis has been first performed. In Fig. 10 the computed drag coefficients at three different mesh sizes, together with a zero mesh size extrapolation, are shown in the case of fully turbulent flow in cruise conditions with and without riblets. The convergence while reducing the mesh size is clearly visible.

The drag polars of the clean configuration and of the configurations equipped with riblets with $l_{g}^{+}=10.5$ (i.e., optimum riblet shape distribution), together with the achieved drag reduction (DR) (pressure and friction contributions), are reported in Fig. 11. The adoption

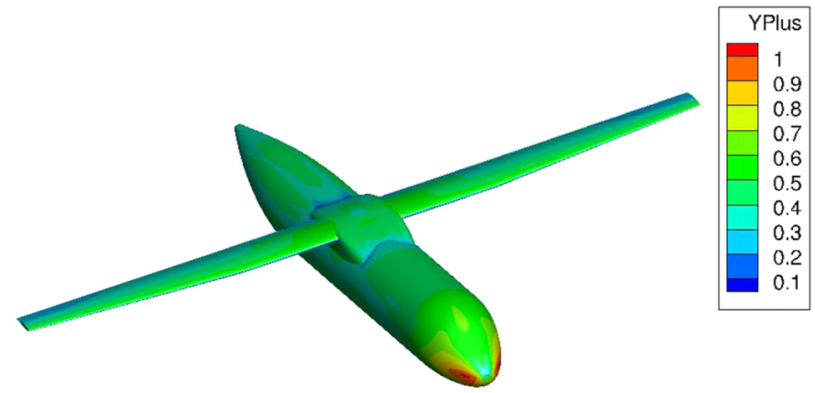

Fig. 9 Regional aircraft configuration: $y^{+}$distribution. in the simulation of the optimum $l_{g}^{+}$value allows for a straightforward a posteriori calculation of the optimum physical size in the different aircraft parts. As verified in [39], the adoption of an average constant physical riblet height in each aircraft part does not significantly reduce the performance.

Riblets only on wing are more effective at the low incidences, whereas riblets only on body provide a gain in drag quite constant with $\alpha$. A combined effect is obtained when riblets are applied over the entire configuration. The percentage drag reduction is calculated as $D R=-\left(C_{D}^{R}-C_{D}^{S} / C_{D}^{S}\right) \times 100$ (where the superscript $R$ stands for riblets and $S$ for smooth), which is about $9 \%$ and decreases with the lift coefficient. It is worth noting that, although the friction drag

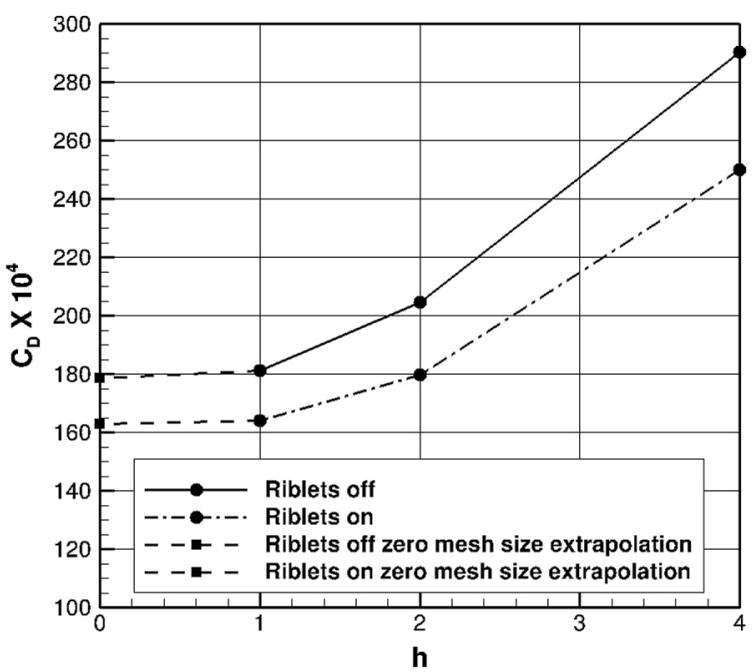

Fig. 10 Regional aircraft configuration: cruise conditions, fully turbulent. Grid convergence study: drag coefficients with and without riblets vs mesh size $h$. 


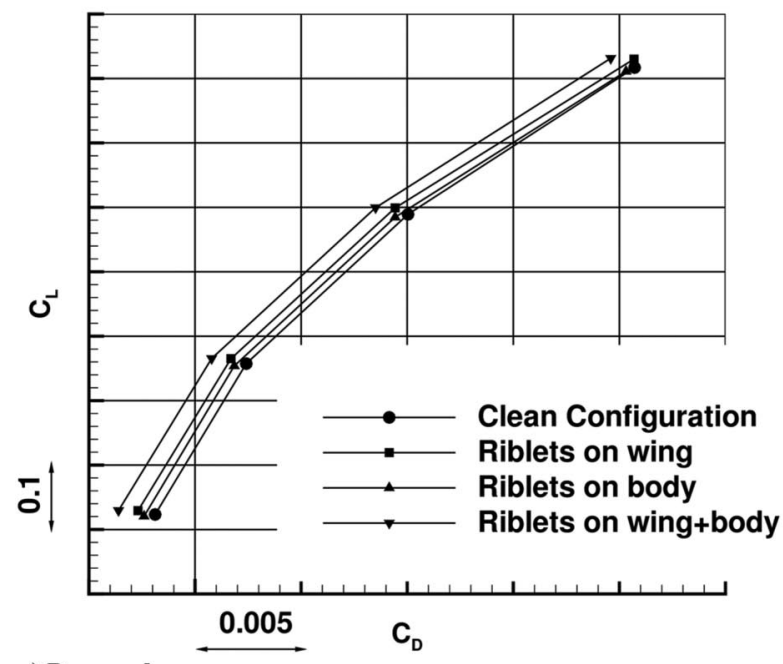

a) Drag polars

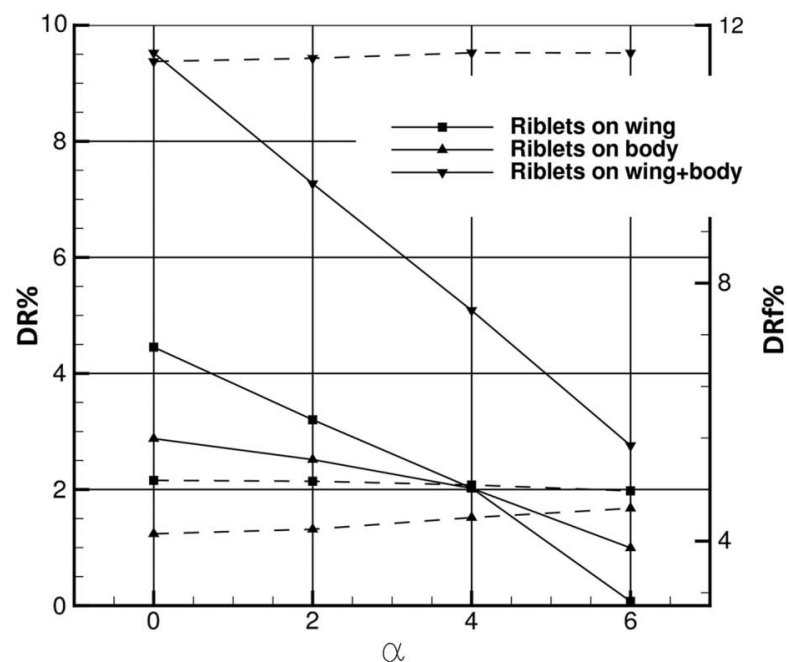

b) Percentage drag reduction by riblets. --: DR, - - -:DRf

Fig. 11 Regional aircraft configuration: cruise conditions.

reduction is substantially constant while varying the angle of attack, the total drag reduction decreases. This effect is linked to the increase of lift-induced drag, on which riblets have no effect, while increasing the angle of attack. The percentage friction drag reduction, calculated as $D R f=-\left(C_{D f}^{R}-C_{D f}^{S} / C_{D f}^{S}\right) \times 100$, is constant with the lift coefficient and is about $11 \%$.

Figure 12 reports the skin friction distribution on the upper surface of the configuration in riblets-on and riblets-off conditions in the case of riblets installed only on the wing. A clear decrease of the skin friction is obtained in the front.

The right plot of Fig. 12 reports, as an example, the $C_{f}$ at a station located at $40 \%$ of the wing span. The gain in $C_{f}$ decreasing as $x$ increases is clearly visible. The riblets-on and clean configuration have the same levels of friction in the trailing-edge region.

The effect of applying the riblets only on the body can be appreciated in Fig. 13.

The zone of the body where the riblets are more effective are the nose and wing-fuselage intersection.

The right plot of Fig. 13 shows the friction distribution along a constant- $y$ section of the body. An effect of riblets, not visible in Fig. 13a, is also present in the rear part of the fuselage.

\section{B. Cruise Conditions with NLF Technology}

The wing of the configuration has been designed to have a laminar flow for a large extent of the wing in cruise conditions. This assumption has been numerically reproduced by imposing a transition at $50 \%$ of the local chord in the outboard zone of the wing. This value has been derived from the results obtained from the design phase [38], where such an extension of laminar flow has been estimated on both surfaces for angles of attack between $0^{\circ}$ and $5^{\circ}$, for a nominal cruise condition around $\alpha=2^{\circ}$. The estimation of transition location has been made by the use of criteria for Tollmien-Schlichting and crossflow instabilities within the iterative convergence process of the CFD computation [40] for the ONERA tool used for the design. The inboard region has been assumed turbulent because the presence of the engines and propeller slipstream is expected to disturb the laminar flow (Fig. 14). Even if the NLF could be partially kept behind the propeller, such as reported in [41], the inboard region has been assumed turbulent as a conservative choice for the computation of the aircraft performance.

The effect of applying the natural flow technology can be appreciated in Fig. 15, where a comparison between the "fully turbulent" (with and without riblets) and NLF configurations is shown. The drag

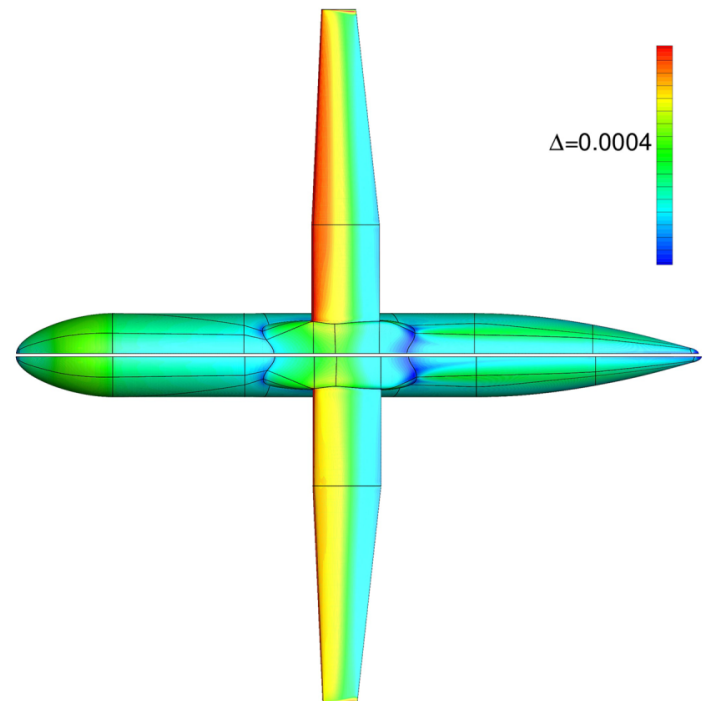

a) $C_{f}$ distribution on upper surface. upper plot: riblets-off; lower plot: riblets-on

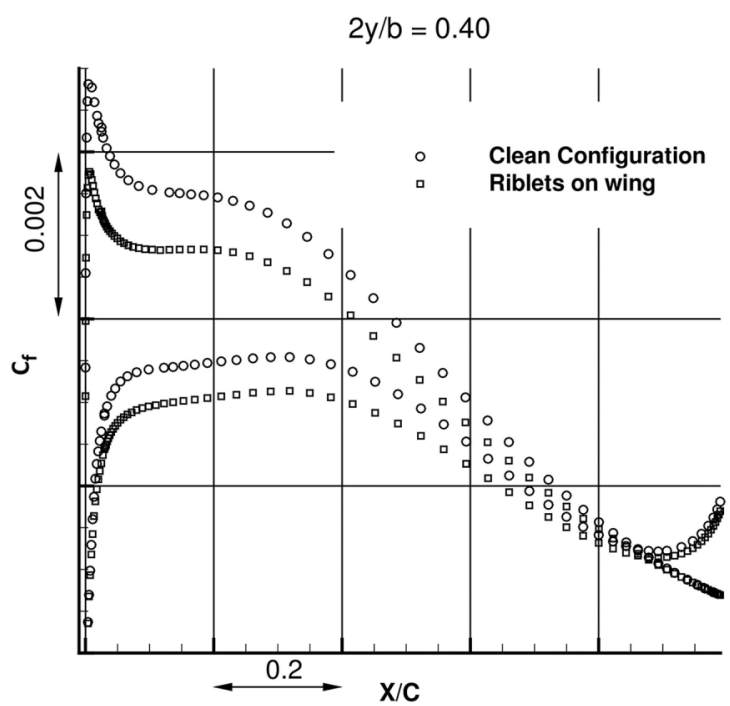

b) $C_{f}$ at spanwise station $2 y / b=0.40$

Fig. 12 Regional aircraft configuration: skin friction coefficient for riblets only on wing. 


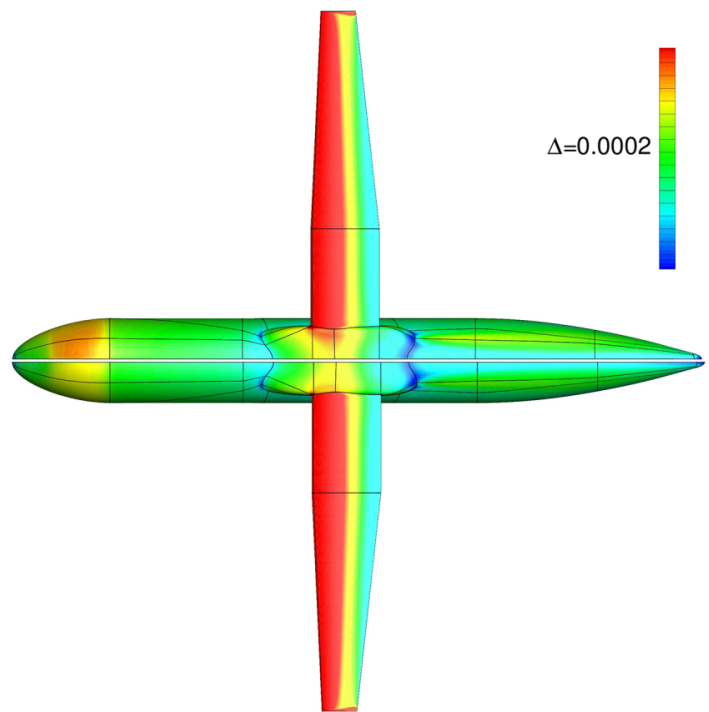

a) $C_{f}$ distribution on upper surface. upper plot: riblets-off; lower plot: riblets-on

Fig. 13 Regional aircraft configuration: skin friction coefficient for riblets only on body.

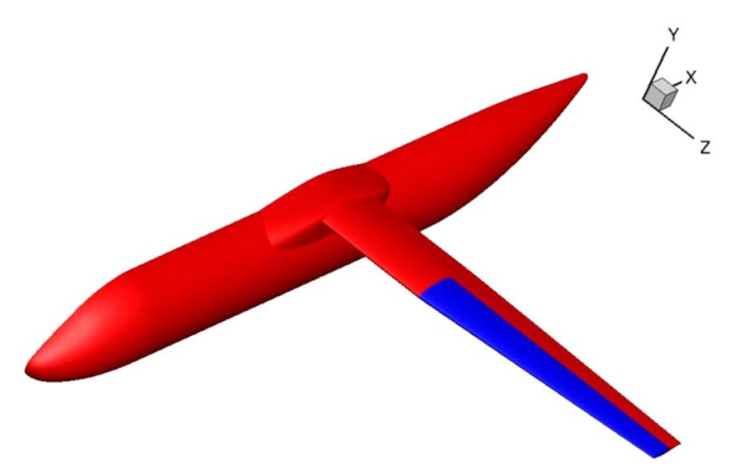

Fig. 14 Regional aircraft configuration: numerically reproducing the natural laminar flow technology. Blue region: laminar; red region: turbulent.

reduction (DR), shown in the right plot, is evaluated with respect to the clean "fully turbulent" configuration. It is worth noting that the drag reduction achieved by the NLF technology and riblet technology are comparable. In percentage, the maximum DR is about $12 \%$ and

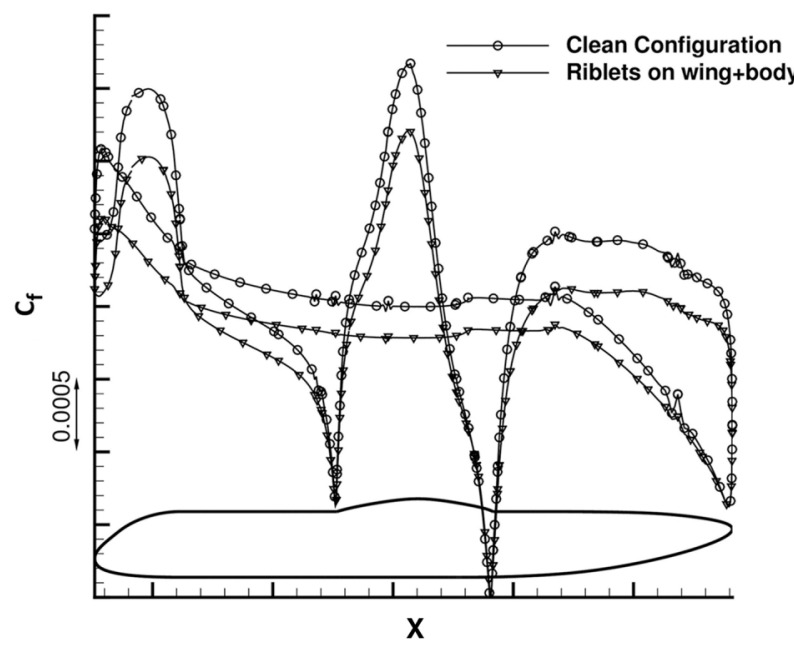

b) $C_{f}$ at a costant-y section of the body 


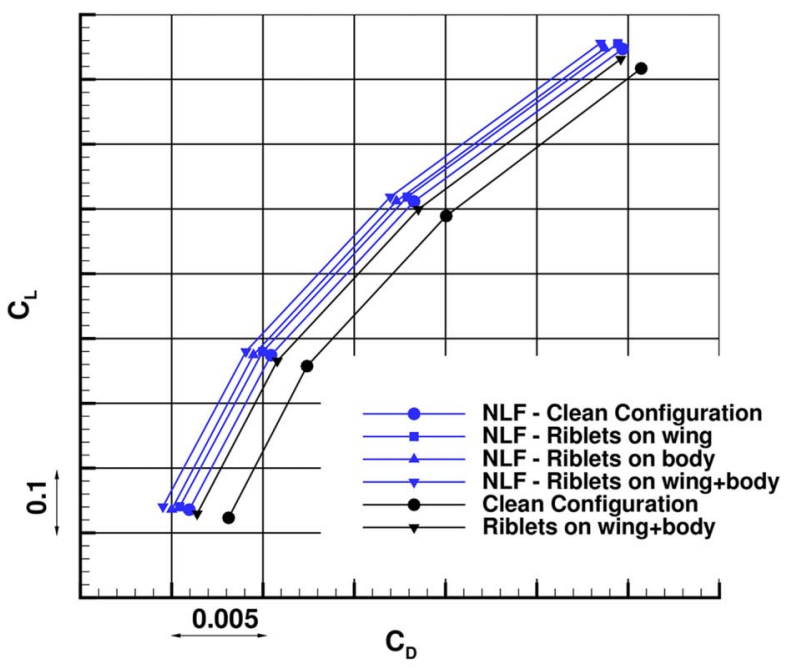

a) Drag polar for "fully turbulent" and NLF configurations plus riblets

Fig. 16 Regional aircraft configuration: cruise conditions with NLF technology plus riblets. —-: DR; - - -: DRf.

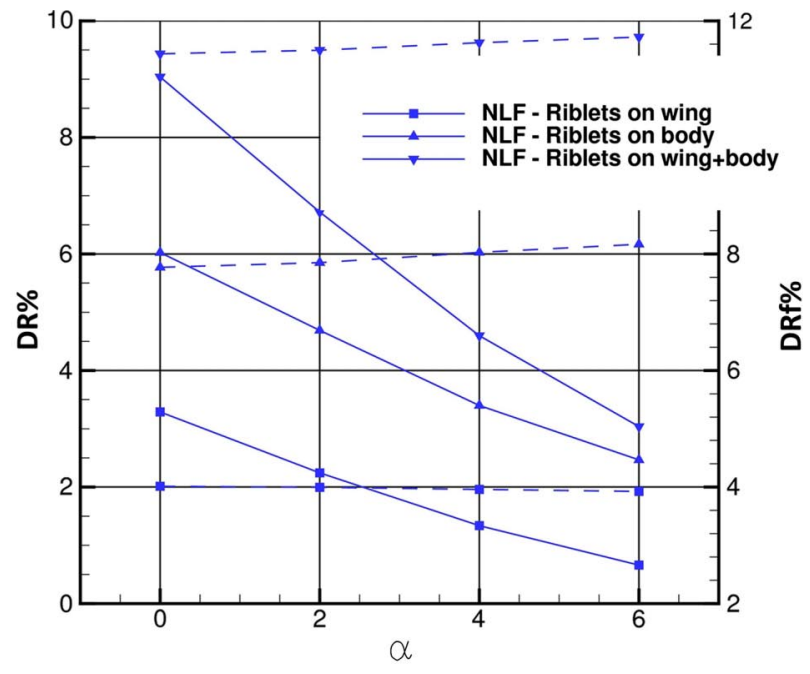

b) Percentage drag reduction by riblets on NLF configuration

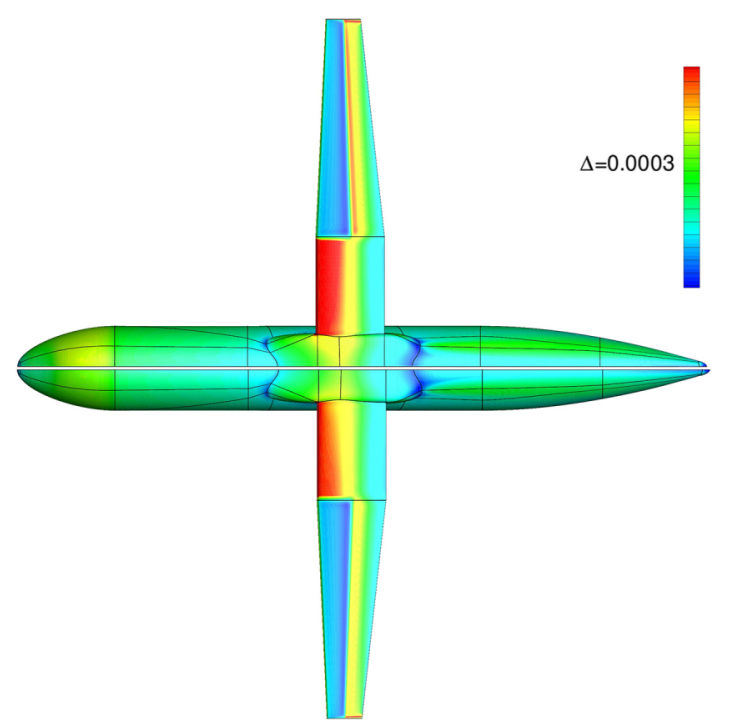

a) $C_{f}$ distribution over the upper surface of the NLF configuration. upper: riblets-off; lower: riblets-on

Fig. 17 Regional aircraft configuration: skin friction with NLF technology and riblets.

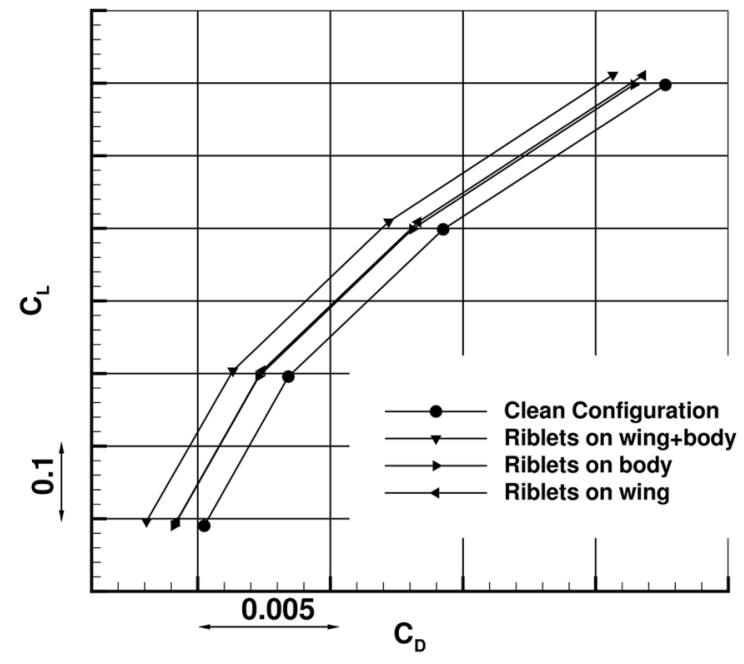

a) Drag polars

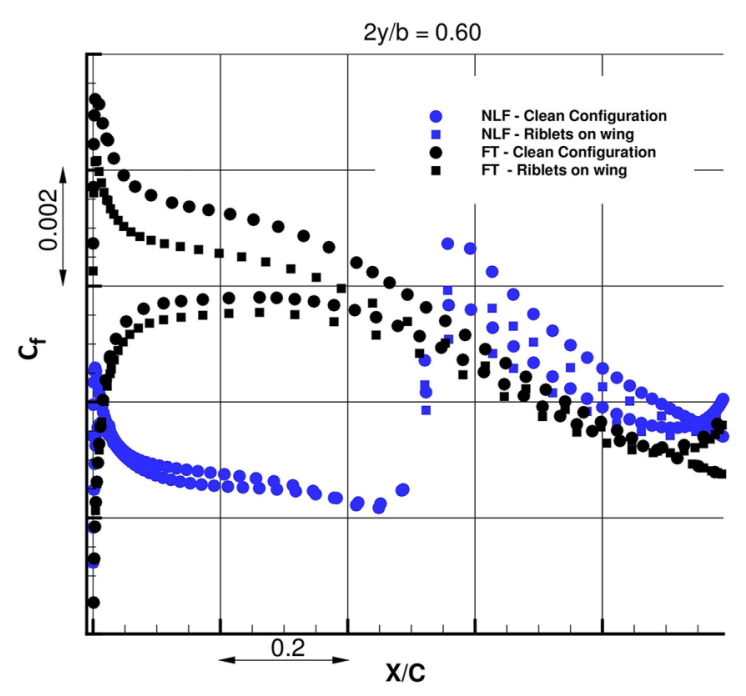

b) $C_{f}$ at the wing station $2 y / b=0.60$

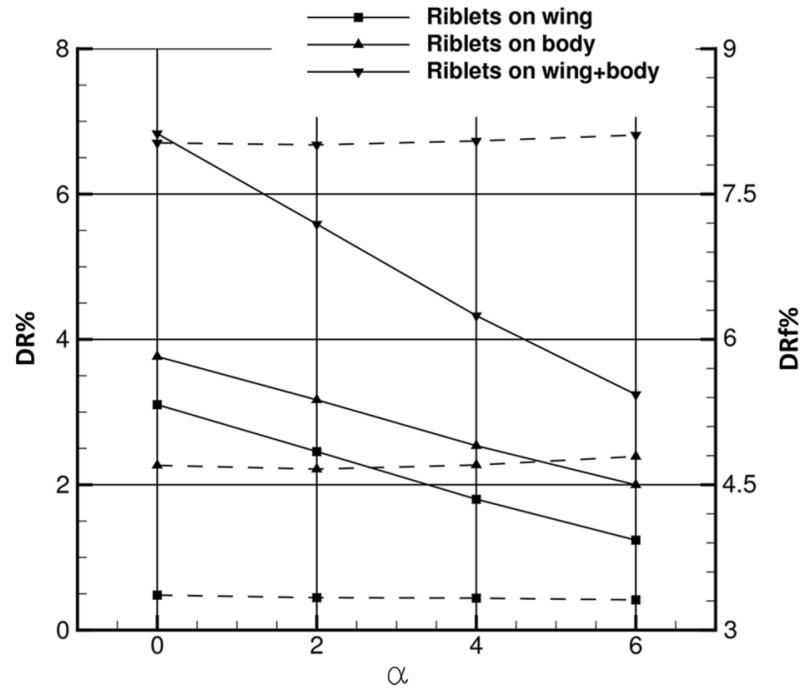

b) Percentage drag reduction by riblets. —-: DR, - - -:DRf 


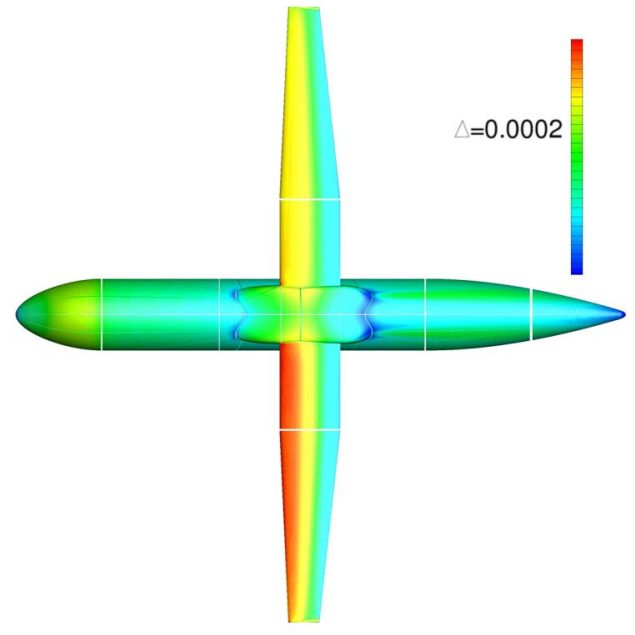

a) $\alpha=2^{\circ}$. Upper: riblets only on wing; lower: riblets-off

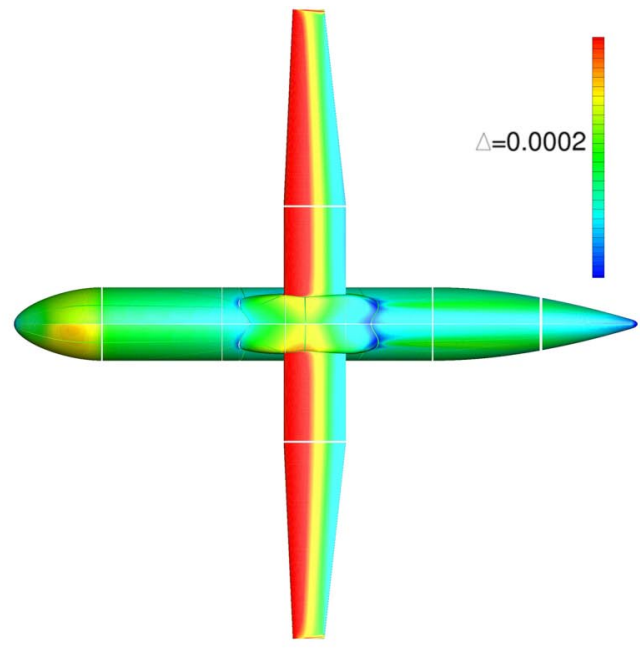

b) $\alpha=4^{\circ}$. Upper: riblets only on body; lower: riblets-off

Fig. 19 Regional aircraft configuration: skin friction distribution in climb conditions.

is larger than friction reduction due to riblets in the same zone. However, the riblets keep their effectiveness in the turbulent region and provide a further gain in $C_{f}$ with respect to the NLF technology.

\section{Climb/Descent Condition}

A flow specification of Mach number 0.20 and Reynolds number (based on the chord of the wing) of $1.30 \times 10^{7}$ has been chosen as representative of a climb/descent condition. Only "fully turbulent" conditions have been taken into consideration. The gain in drag coefficient in climb conditions is shown in Fig. 18. The "optimum" riblets have been applied on wing, on body, and on the entire configuration. In terms of drag reduction, riblets on wing have a similar effect as the riblets on body. The maximum drag reduction is achieved when riblets are applied on wing and fuselage and results to be about $7 \%$ and decreases with the incidence. The friction drag reduction is about $8 \%$ and is constant with the $\alpha$. It is worth noting that, even if the maximum drag reduction is slightly reduced compared with cruise conditions, riblet effectiveness is still good.

Finally, the contour plot of the friction coefficient over the upper surface is presented in Fig. 19. Again, the riblets are effective in the front part of the wing with an effect quite constant in the spanwise direction and in the region of the nose of the body and of the wingbody intersection.

\section{Estimate of Gain for an Operative Day of Regional Aircraft Configuration}

In the previous sections the drag reduction achieved by NLF and riblet technologies has been computed in various conditions. It has been shown that in cruise conditions riblets technology alone can reduce drag up to $9 \%$, NLF alone can reduce drag up to $12 \%$, and the combined installation of both technologies induces a drag reduction up to $20 \%$. The previous discussed results are here applied to evaluate the weight that a new-generation turboprop could save in a typical mission, as a means of having operative information on the benefits that such technologies can lead.

The Breguet formula for the range

$$
R=\frac{\eta}{c_{s}} \frac{C_{L}}{C_{D}} \ln \frac{W_{i}}{W_{f}}
$$

is applied with the aerodynamic coefficients retrieved by the drag polars presented in the previous sections. The analysis is restricted only to the cruise part of a typical mission (Fig. 20a) with $W_{i}$ the weight at the end of the climb phase and $W_{f}$ the weight at the end of the cruise phase.

A lift coefficient of 0.50 is considered, whereas the $C_{D}$ is estimated by the values of the drag coefficient of the wing-body configuration $C_{D}^{W B}$. This is obtained by considering the drag breakdown of a typical turboprop-driven aircraft as shown in Fig. 20b, where "other" is represented by interferences, windshield, gaps, excrescences, and so on. This miscellaneous contribution is generally estimated considerably larger than that in the case of advanced transonic jet-liners, which are characterized by a more refined aerodynamics. The typical contribution of the wing-body to the total drag coefficient, as derived by Fig. 20 b, is

$$
C_{D}^{W B}=C_{D}^{W}+C_{D}^{B}=0.68 * C_{D}
$$

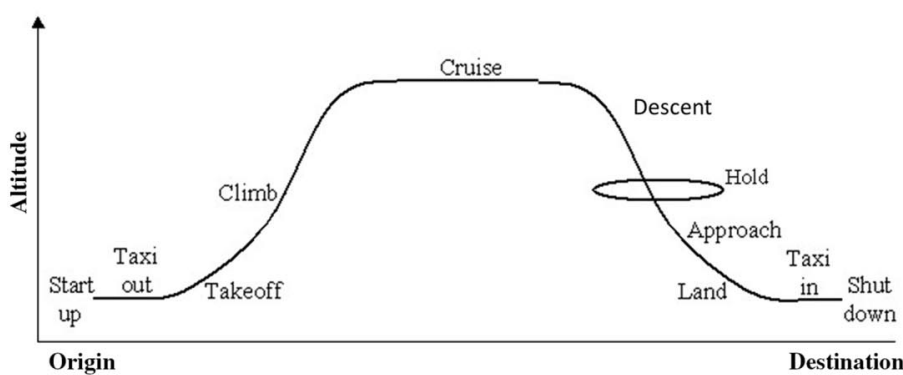

a) Mission
Destination

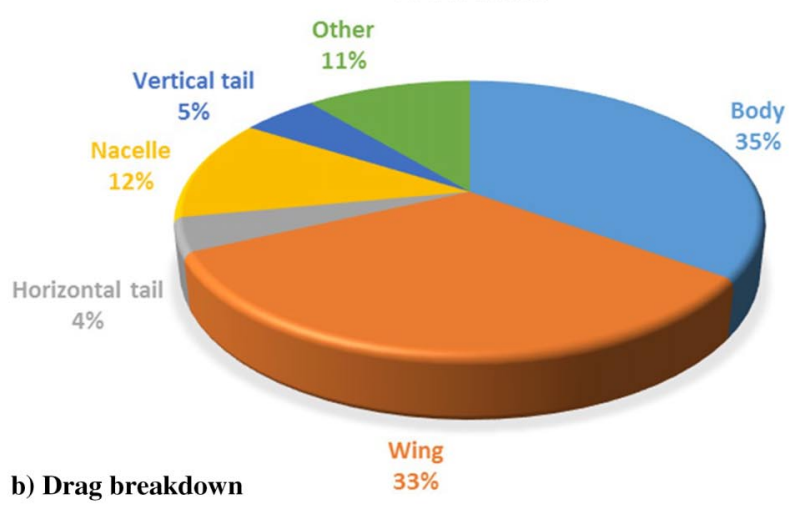


Table 1 Saving of weight for a design mission with cruise phase of $900 \mathrm{NM}$

\begin{tabular}{ccccccc}
\hline \hline & Clean & Riblets W & Riblets B & Riblets WB & NLF & NLF + Riblets WB \\
\hline $100 * \Delta W / W_{f}^{c}$ & 0 & 4.02 & 1.86 & 7.89 & 10.52 & 17.03 \\
\hline \hline
\end{tabular}

Table 2 Saving of weight for a typical mission with cruise phase of $350 \mathrm{NM}$

\begin{tabular}{ccccccc}
\hline \hline & Clean & Riblets W & Riblets B & Riblets WB & NLF & NLF + Riblets WB \\
\hline $100 * \Delta W / W_{f}^{c}$ & 0 & 1.58 & 0.73 & 3.10 & 4.13 & 6.68 \\
\hline \hline
\end{tabular}

Each contribution to the total drag can be expressed as function of the $C_{D}^{W B}$ exploiting Eq. (11) as (e.g., for the horizontal tail):

$$
C_{D}^{H T}=0.04 * C_{D}=\frac{0.04}{0.68} * C_{D}^{W B}=0.059 * C_{D}^{W B}
$$

and therefore

$$
C_{D}=C_{D}^{W B}+C_{D}^{H T}+C_{D}^{V T}+C_{D}^{N a}+C_{D}^{O t}=1.47 * C_{D}^{W B}
$$

The drag coefficient, evaluated by Eq. (13) by exploiting the drag polars computed for the wing-body configuration, is used in Eq. (10), where $\eta$ is the efficiency of the propeller and $c_{s}$ is the specific fuel consumption. The values considered typical for a turbopropellerdriven aircraft are $\eta=0.85$ and $c_{s}=0.70(\mathrm{lb} / \mathrm{hph})$. The difference in weight $\Delta W$ that can be achieved by riblets and NLF technology has been computed with respect to $W_{f}^{c}$, the weight at the end of the cruise phase of the clean configuration.

The percentage saving weight of a turboprop regional aircraft has been estimated and reported in Table 1 for a design mission with a cruise of 900 nautical miles (NM) and in Table 2 for typical mission with a cruise of $350 \mathrm{NM}$. The saving is due to the reduction of the cruise fuel weight.

The analysis reported above suffers from some assumptions especially with regard to the evaluation of the drag coefficient. However, it is possible to state that the NLF technology would allow to save more weight than riblets, about $30 \%$ more. It is also worth noting that, in terms of saving weight, riblets on wing are more effective (almost two times) than riblets on fuselage.

\section{Conclusions}

The effect of application of the riblets to a new-generation turboprop configuration has been presented. The wing of the configuration has been designed with the aim to have NLF in cruise conditions, then the riblets have been considered also in conjunction with the NLF technology. RANS simulations have been performed by exploiting a proper boundary condition to simulate the effect of the riblets. Twodimensional test cases have been first discussed comparing the results with available experiments. Then, riblets and NLF performance on a wing-body turboprop configuration have been calculated in various conditions. Drag polars in cruise and climb/descent conditions and drag reduction variation with the angle of attacks have been computed. The results show how riblets and NLF technologies have comparable performance when applied alone and that the combined application of both returns a maximum drag reduction of $20 \%$ in cruise conditions. Riblets are effective also in climb/descent conditions, but the maximum drag reduction is slightly reduced to $7 \%$. The weight that a turbopropeller-driven aircraft could save by applying these drag reduction techniques in the cruise phase of a typical mission has been also estimated, providing operative details on the achievable benefits.

\section{Acknowledgment}

The research leading to these results has received funding from Clean Sky 2 Joint Undertaking under the European Union's Horizon 2020 research and innovation program under grant agreement CS2-REG-GAM-2014-2015-01.

\section{References}

[1] Walsh, M. J., and Weinstein, L. M., "Drag and Heat-Transfer Characteristics of Small Longitudinally Ribbed Surfaces," AIAA Journal, Vol. 17, No. 7, 1979, pp. 770-771.

https://doi.org/10.2514/3.61216

[2] Walsh, M. J., "Riblets," Viscous Drag Reduction in Boundary Layers, Progress in Astronautics and Aeronautics, Vol. 123, edited by D. M. Bushnell, and J. N. Hefner, AIAA, Washington, D.C., 1990, pp. 203-261.

[3] Bechert, D., Bruse, M., and Hage, W., "Experiments with ThreeDimensional Riblets as an Idealized Model of Shark Skin," Experiments in Fluids, Vol. 28, No. 5, 2000, pp. 403-412. https://doi.org/10.1007/s003480050400

[4] Bechert, D., Bruse, M., Hage, W., van der Hoeven, J., and Hoppe, G., "Experiments on Drag-Reducing Surfaces and Their Optimization with an Adjustable Geometry," Journal of Fluid Mechanics, Vol. 338, May 1997, pp. 59-87. https://doi.org/10.1017/S0022112096004673

[5] Luchini, P., Manzo, F., and Pozzi, A., "Resistance of Grooved Surface to Parallel Flow and Cross-Flow," Journal of Fluid Mechanics, Vol. 228, April 1991, pp. 87-109.

[6] Sundaram, S., Viswanath, P. R., and Rudrakumar, S., "Viscous Drag Reduction Using Riblets on NACA 0012 Airfoil to Moderate Incidence," AIAA Journal, Vol. 34, No. 4, 1996, pp. 676-682. https://doi.org/10.2514/3.13127

[7] Raju, C., and Viswanath, P., "Base Drag Reduction Caused by Riblets on a GAW(2) Airfoil," Journal of Aircraft, Vol. 35, No. 6, 1998, pp. 988-991. https://doi.org/10.2514/2.2403

[8] Viswanath, P., "Aircraft Viscous Drag Reduction Using Riblets," Progress in Aerospace Sciences, Vol. 38, Nos. 6-7, 2002, pp. 571-600. https://doi.org/10.1016/S0376-0421(02)00048-9

[9] Chamorro, L., Arndt, R., and Sotiropoulos, F., "Drag Reduction of Large Wind Turbine Blades Through Riblets: Evaluation of Riblet Geometry and Application Strategies," Renewable Energy, Vol. 50, Feb. 2013, pp. 1095-1105.

https://doi.org/10.1016/j.renene.2012.09.001

[10] Sareen, A., Deters, R., Henry, S., and Selig, M., "Drag Reduction Using Riblet Film Applied to Airfoils for Wind Turbines," Journal of Solar Energy Engineering, Vol. 136, No. 2, 2014, Paper 021007. https://doi.org/10.1115/1.4024982

[11] Nieuwstadt, F., Wolthers, W., Leijdens, H., Krishna Prasad, K., and van Manen, S., "The Reduction of Skin Friction by Riblets Under the Influence of an Adverse Pressure Gradient," Experiments in Fluids, Vol. 15, No. 1, 1993, pp. 17-26. https://doi.org/10.1007/BF00195591

[12] Debisschop, J., and Nieuwstadt, F., "Turbulent Boundary Layer in an Adverse Pressure Gradient: Effectiveness of Riblets," AIAA Journal, Vol. 34, No. 5, 1996, pp. 932-937. https://doi.org/10.2514/3.13170

[13] Boomsma, A., and Sotiropoulos, F., "Riblet Drag Reduction in Mild Adverse Pressure Gradient: A Numerical Investigation," International Journal of Heat and Fluid Flow, Vol. 56, No. 56, 2015, pp. 251-260. https://doi.org/10.1016/j.ijheatfluidflow.2015.07.022

[14] Koeplin, V., Herbst, F., and Seume, J., "Correlation-Based Riblet Model for Turbomachinery Applications," Journal of Turbomachinery, Vol. 139, No. 7, 2017, Paper 071006.

[15] Mele, B., and Tognaccini, R., "Slip Length Based Boundary Condition for Modeling Drag Reduction Devices," AIAA Journal, Vol. 56, No. 9, 2018, pp. 3478-3490.

https://doi.org/10.2514/1.J056589

[16] Catalano, P., and Tognaccini, R., "Turbulence Modelling for Low Reynolds Number Flows," AIAA Journal, Vol. 48, No. 8, 2010, pp. 1673-1685. https://doi.org/10.2514/1.J050067 
[17] Catalano, P., and Tognaccini, R., "RANS Analysis of the Low-Reynolds Number Flow Around the SD7003 Airfoil," Aerospace Science and Technology, Vol. 15, No. 8, 2011, pp. 615-626. https://doi.org/10.1016/j.ast.2010.12.006

[18] Mele, B., and Tognaccini, R., "Numerical Simulation of Riblets on Airfoils and Wings," 50th AIAA Aerospace Sciences Meeting Including the New Horizons Forum and Aerospace Exposition, AIAA Paper 20120861, 2012.

[19] Catalano, P., Mele, B., and Tognaccini, R., "On the Implementation of a Turbulence Model for Low Reynolds Number Flows," Computers and Fluids, Vol. 109, March 2015, pp. 67-71.

https://doi.org/10.1016/j.compfluid.2014.12.009

[20] Catalano, P., and Tognaccini, R., "Influence of Free-Stream Turbulence on Simulations of Laminar Separation Bubbles," 47th AIAA Aerospace Sciences Meeting and Exhibit, AIAA Paper 2009-1471, 2009.

[21] Mele, B., Tognaccini, R., and Catalano, P., "Effect of Riblets on a Complex Configuration in Transonic Conditions," European Drag Reduction and Flow Control Meeting - EDRFCM 2015, Univ. of Cambridge, Cambridge, U.K., 2015.

[22] Mele, B., and Tognaccini, R., "A Unified Model for Riblet Simulation in Complex Flows," XXI Congresso AIMETA, Associazione Italiana di Meccanica Teorica e Applicata, AXEA SAS, Libreria Cortina, Torino, Italy, 2013.

[23] Mele, B., Tognaccini, R., and Catalano, P., "Analyses of Non Local Effects of Riblets," Aerotecnica Missili \& Spazio, The Journal of Aerospace Science, Technology and Systems., Vol. 95, No. 4, 2016, pp. 232-247. https://doi.org/10.1007/BF03404731

[24] Mele, B., Tognaccini, R., and Catalano, P., "Performance Assessment of a Transonic Wing-Body Configuration with Riblets Installed," Journal of Aircraft, Vol. 53, No. 1, 2016, pp. 129-140. https://doi.org/10.2514/1.C033220

[25] Tognaccini, R., Mele, B., Catalano, P., and Mele, B., "Riblets: Ready for Application on Next Generation Aircrafts?" Greener Aviation 2016, 3AF, Paris, France, 2016.

[26] Hage, W., Stenzel, V., and Vynnyk, T., Investigation of the Wear Properties of a Riblet Paint Structure on an Airbus A300-600ST Beluga, New Results in Numerical and Experimental Fluid Mechanics VIII, Vol. 121, Springer, Berlin, 2013, pp. 185-192.

[27] Bilinsky, H., "Direct Contactless Microfabrication of 3D Riblets: Improved Capability and Metrology," 2019 AIAA Scitech Forum, AIAA Paper 2019-1626, 2019. https://doi.org/10.2514/6.2019-1626

[28] Felder, W., Dale, G., and Cash, C., "Practical Viscous Drag Reduction: Charting a Course out of the Valley," 2019 AIAA Scitech Forum, AIAA Paper 2019-1623, 2019. https://doi.org/10.2514/6.2019-1623

[29] Catalano, P., de Rosa, D., Mele, B., Tognaccini, R., and Moens, F., "Influence of Riblets and Laminar Flow Control on the Performances of a Regional Aircraft," European Drag Reduction and Flow Control Meeting_EDRFCM 2017, POLIMI, Milano, Italy, 2017.

[30] Jiménez, J., "Turbulent Flows over Rough Walls," Annual Review Fluid Mechanics, Vol. 36, No. 1, 2004, pp. 173-196. https://doi.org/10.1146/annurev.fluid.36.050802.122103

[31] Tani, I., "Drag Reduction by Riblet Viewed as Roughness Problem," Proceedings of the Japan Academy, Vol. 64, The Japan Academy, Japan, 1988, pp. 21-24.

[32] Nikuradse, J., "Laws of Flow in Rough Pipes," NACA TM-1292, Nov. 1950.

[33] Wilcox, D. C., Turbulence Modeling for CFD, 2nd ed., DCW Industries, La Canada, CA, 1998, Chap. 4.

[34] Saffman, P., "A Model for Inhomogeneous Turbulent Flow," Proceedings of the Royal Society, Vol. 317, Royal Soc., Great Britain, 1970, pp. 417-433.

[35] García-Mayoral, R., and Jiménez, J., "Drag Reduction by Riblets," Philosophical Transactions of the Royal Society A, Vol. 369, No. 1940, 2011, pp. 1412-1427. https://doi.org/10.1098/rsta.2010.0359

[36] Coustols, E., and Schmitt, V., "Synthesis of Experimental Riblet Studies in Transonic Conditions," Turbulence Control by Passive Means, edited by E. Coustols, 4th European Drag Reduction Meeting, Springer, Dordrecht, 1990, pp. 123-140.

[37] Salah, I., Godard, J., Rodde, A., Moens, F., Andreutti, G., de Rosa, D., Di Muzio, M., Gemma, R., Baldassin, E., Calvi, N., and Averardo, M., "Natural Laminar Flow Transonic Wing Design Applied to Future Innovative Green Reegional Aircraft," AAAF-CEAS Greener Aviation Conference, HAL CCSD, Brussels, Belgium, 2014.

[38] De Gasapari, A., and Moens, F., "Aerodynamic Shape Design and Validation of an Advanced High-Lift Device for a Regional Aircraft with Morphing Droop Nose," Hindawi International Journal of Aerospace Engineering, Vol. 2019, March 2019, Paper 7982168. https://doi.org/10.1155/2019/7982168

[39] Mele, B., Tognaccini, R., and Catalano, P., "Performance Assessment of a Transonic Wing-Body Configuration with Riblets Installed," Journal of Aircraft, Vol. 53, No. 1, 2016, pp. 129-140. https://doi.org/10.2514/1.C033220

[40] Moens, F., Perraud, J., Krumbein, A., Toulorge, T., Iannelli, P., Eliasson, P., and Hanifi, A., "Transition Prediction and Impact on 3D High-Lift Wing Configuration," Journal of Aircraft., Vol. 45, No. 5, 2008, pp. 1751-1766. https://doi.org/10.2514/1.36238

[41] Wohlrath, W., Echtle, H., Dick, P., Welte, D., Stock, H. W., Moeken, B., Horstmann, K. H., Muller, R., Rohardt, C. H., and Quast, A., "Design and Flight Test Evaluation of a Laminar Wing Glove on a Commuter Aircraft," 1994 ICAS Conference, International Council of the Aeronautical Sciences Paper 94-5.5.4.1, 1994. 